\title{
Aplicação de índices para avaliação da qualidade da água da Bacia Costeira do Sapucaia em Sergipe
}

\author{
Application of indexes to assess the water \\ quality of coastal basin of the Sapucaia in Sergipe
}

\author{
Rosa Cecilia Lima Santos', Álvaro Silva Lima², Eliane Bezerra Cavalcanti ${ }^{3}$, \\ Cláudia Moura de Melo ${ }^{4}$, Maria Nogueira Marques ${ }^{5}$
}

口-

\section{RESUMO}

A redução da disponibilidade qualiquantitativa da água no mundo está diretamente relacionada às formas de uso e ocupação do solo, aos processos produtivos da agricultura e da pecuária, ao processo de urbanização e à geração de efluentes domésticos e industriais. Por isso, é importante a realização de diagnósticos de bacias hidrográficas, sobre o uso e a ocupação de seu solo e sobre a qualidade da água como ferramenta para a gestão hídrica. Este estudo teve como objetivo caracterizar e monitorar a qualidade da água da Bacia Costeira do Sapucaia, Sergipe. As coletas foram realizadas em oito pontos, com periodicidade trimestral, de agosto de 2014 a setembro de 2015. Na avaliação da qualidade da água foram utilizados: o Índice de Qualidade da Água (IQA) e o Índice de Estado Trófico (IET). As análises das amostras foram realizadas de acordo com os procedimentos estabelecidos no Standard Methods, sendo analisados os seguintes parâmetros: coliformes totais e termotolerantes, turbidez, $\mathrm{pH}$, oxigênio dissolvido, sólidos totais, fósforo total, nitrogênio total, temperatura, condutividade, demanda bioquímica de oxigênio e clorofila. Os resultados do IQA classificam os corpos d'água em aceitável (2,5\%), bom (92,5\%) e ótimo (5,0\%). Os resultados do IET classificaram as amostras como: ultraoligotrófico (67,5\%), oligotrófico (20,0\%), mesotrófico (2,5\%), eutrófico (7,5\%) e supereutrófico (2,5\%). Os resultados obtidos permitem afirmar que os rios Aningas, Sapucaia e a Lagoa Redonda apresentam baixo grau de degradação, com menor conservação do ponto amostral localizado no Rio Sapucaia, dentro da Reserva Santa Isabel, por ser uma área bastante visitada nos finais de semana e feriados.

Palavras-chave: recursos hídricos; qualidade de água; meio ambiente.

\begin{abstract}
The reduction of quali-quantitative availability of water in the world is directly related to the forms of land use and occupation, the productive processes of agriculture and cattle raising, the process of urbanization and the generation of domestic and industrial effluents. Thus, it is important to evaluate hydrographic basins regarding the use and occupation of their land and water quality as a tool for water management. This study aimed to characterize and monitor the quality of water of the Sapucaia Coastal Basin in the state of Sergipe, Brazil. The collections were performed quarterly in eight points of the basin, from August 2014 to September 2015. In the assessment of water quality, the Water Quality Index (WQI) and the Trophic State Index (TSI) were used. The analyzes of the samples were carried out according to the procedures outlined in Standard Methods; the following parameters were analyzed: total and fecal coliforms, turbidity, pH, dissolved oxygen, total solids, total phosphorus, total nitrogen, temperature, conductivity, biochemical oxygen demand and chlorophyll. The results from the application of the WQI classified water bodies as acceptable (2.5\%), good (92.5\%) and very good (5.0\%). The results of the TSI ranked the samples as ultraoligotrophic (67.5\%), oligotrophic (20.0\%), mesotrophic (2.5\%), eutrophic (7.5\%) and supereutrophic (2.5\%). The results allow to affirm that Aningas and Sapucaia rivers and Lagoa Redonda pond, belonging to the Sapucaia Coastal Basin, in Sergipe, have a low degree of degradation, with lower conservation of the sample point located in Sapucaia river, within the Reserva Santa Isabel reserve, that being a widely visited area on weekends and holidays.
\end{abstract}

Keywords: water resources; water quality; environment.

\footnotetext{
口-

'Mestranda do Programa de Pós-graduação em Saúde e Ambiente da Universidade Tiradentes (UNIT) - Aracaju (SE), Brasil. Bióloga pela Universidade Federal de Sergipe (UFS) - Aracaju (SE), Brasil.

2Pós-doutor pela Universidade de Aveiro (UA) - Aveiro, Portugal. Professor do Programa de Pós-graduação em Engenharia de Processos da UNIT e do Instituto de Tecnologia e Pesquisa (ITP) - Aracaju (SE), Brasil.

${ }^{3}$ Doutora em Engenharia Eletroquímica pela Université de Rennes I- Rennes, França. Professora do Programa de Pós-graduação em Engenharia de Processos da UNIT e do ITP - Aracaju (SE), Brasil.

${ }^{4}$ Doutora em Parasitologia pela Universidade Estadual de Campinas (UNICAMP) - Campinas (SP), Brasil. Coordenadora do Programa de Pós-graduação em Saúde e Ambiente da UNIT - Aracaju (SE), Brasil.

${ }^{5}$ Doutora em Tecnologia Nuclear pelo Instituto de Pesquisas Energéticas e Nucleares (IPEN) - São Paulo (SP), Brasil. Professora do Programa de Pós-graduação em Saúde e Ambiente da UNIT - Aracaju (SE), Brasil.

Endereço para correspondência: Cláudia Moura de Melo - Avenida Murilo Dantas, 300 - Farolândia - 49032-490 - Aracaju (SE), Brasil - E-mail: cludiamouramelo@hotmail.com Recebido em: 13/04/16 - Aceito em: 22/11/16 - Reg. ABES: 159832
} 


\section{INTRODUÇÃO}

A água tem se tornado o recurso mais estratégico de qualquer país devido a alguns fatores, como o crescimento da população, a expansão urbanística, a industrialização, a agricultura, a pecuária e a produção de energia elétrica. O aumento em sua demanda fez com que quantidades crescentes de água fossem exigidas. Nos últimos 60 anos, esses processos foram acrescidos de um ciclo de poluição (para cada mil litros de água utilizados, outros dez mil são poluídos), o que torna a água um recurso precioso (BRASIL, 2011).

No Brasil, apesar do uso mais nobre dos recursos hídricos estar relacionado ao consumo humano, os corpos hídricos das bacias hidrográficas têm apresentado progressiva degradação da qualidade de suas águas, gerando variados conflitos pelo uso da água. Os principais tipos de conflito são devido a barramentos dos cursos d'água na bacia, feitos ilegalmente por proprietários de terras, retiradas de vazões de água com/sem outorga, exploração mineral, extração de areia e pedras e lixiviação de resíduos de agrotóxicos oriundos de cultivos agrícolas feitos nas margens ou no entorno dos rios (SOARES, 2008).

Lidar com recursos hídricos escassos é uma realidade da região nordeste brasileira; no entanto, lidar com a degradação dos corpos hídricos é a realidade de várias regiões do país. Para enfrentar esses desafios, é preciso estudar a bacia hidrográfica como um todo, considerando, dentre outros elementos, a geomorfologia, assim como também deve ser estudada a relação homem versus natureza, uma vez que as ações antrópicas influenciam na dinâmica natural de bacias hidrográficas (MELO E SOUZA, 2009).

As bacias hidrográficas apresentam uma grande heterogeneidade em seus elementos naturais. Os problemas que se estabelecem em uma bacia hidrográfica podem ser vistos em outras bacias. Aos poucos, os rios vêm sendo degradados, tornando-se um dos maiores desafios na atualidade. Dentre os vários ecossistemas, o aquático é o mais importante e seus aspectos bióticos e abióticos devem ser estudados de forma prioritária. As características físicas da água a torna um meio de transporte de determinadas substâncias e elementos químicos tóxicos, além de microrganismos patogênicos, limitando seu consumo para alguns usos específicos (VON SPERLING, 2007).

O uso e a ocupação do solo influenciam a qualidade da água de uma bacia hidrográfica, mesmo com suas condições naturais preservadas, pois a composição da água pode ser afetada pela declividade superficial e pela infiltração no solo de despejos domésticos e/ou defensivos agrícolas. Em vista disso, a forma de utilização dos recursos hídricos e o despejo de substâncias tóxicas nos corpos d'água têm demandado constantes estudos de monitoramento e atenção especial dos gestores ambientais (MARQUES et al., 2007).

Os recursos hídricos brasileiros vêm sendo gerenciados pela Lei ${ }^{\circ}$ 9.433/1997, que institui a bacia hidrográfica como unidade de planejamento. Em 1997, o estado de Sergipe implantou a Lei no 3.870, que discorre acerca da Política Estadual de Recursos Hídricos, objetivando assegurar às atuais e futuras gerações a disponibilidade de água em padrões de qualidade e quantidade adequados aos respectivos usos.
O estado possui oito bacias hidrográficas, que são as bacias do Rio São Francisco, Rio Vaza Barris, Rio Real, Rio Japaratuba, Rio Sergipe, Rio Piauí, Bacia Costeira do Sapucaia (BCS) e Bacia Costeira Caueira Abais (GOVERNO DO ESTADO DO SERGIPE, 2015).

Este trabalho tem como cerne apresentar análises físico-químicas e microbiológicas, além do estado trófico das águas da BCS, identificando os problemas que interferem no padrão de qualidade da água. A caracterização de bacias hidrográficas, particularmente por meio de análises hidrológicas, poderá levar ao melhor entendimento da dinâmica ambiental local e/ou regional.

\section{METODOLOGIA}

\section{Área de Estudo}

A BCS situa-se no litoral norte do estado de Sergipe, distribuída no Território Leste Sergipano (municípios de Japaratuba e Pirambu) e Território Baixo São Francisco (município de Pacatuba), entre as bacias hidrográficas do Rio São Francisco e Rio Japaratuba. A BCS ocupa uma área de 118,33 km² e é constituída pelos rios Aningas e Sapucaia (GOVERNO DO ESTADO DO SERGIPE, 2015).

Após as visitas a campo e escolha dos pontos de amostragem, confeccionou-se o mapa da área da drenagem da Bacia Costeira 1, em um software com sistema de informação geográfica (SIG), o Sistema de Processamento de Informações Georeferenciadas (SPRING) versão 5.1.8 (Figura 1 e Tabela 1)

No período de agosto de 2014 a setembro de 2015 foram coletadas, trimestralmente, amostras de águas superficiais em oito pontos na área de drenagem da BCS. Para os procedimentos de coleta $\mathrm{e}$ armazenamento das amostras, utilizou-se o Guia Prático de Coleta do Laboratório de Ensaios Ambientais (LEA).

As análises foram realizadas no Instituto de Tecnologia de Pesquisa (ITP), especificamente no LEA e no Laboratório de Pesquisa e Alimentos (LPA). As determinações analíticas foram realizadas de acordo com os procedimentos estabelecidos no Standard Methods, descritos na Tabela 2 (APHA; AWWA; WEF, 2012).

Realizou-se uma avaliação da variação espacial e temporal dos parâmetros analisados nas amostras de água, bem como uma avaliação simplificada desses dados utilizando o Índice de Qualidade de Água (IQA) e o Índice de Estado Trófico (IET), ambos adotados pela Agencia Nacional de Águas (ANA). Uma das vantagens de se utilizar índices é facilitar a interpretação dos dados pelo público leigo, por representar uma média de diversas variáveis em um único número, combinado de unidades de medidas diferentes (CETESB, 2009).

\section{Índice de Qualidade de Água}

O IQA é o mesmo adotado pela ANA, que é uma adaptação do índice de qualidade de água da National Sanitation Foundation (NSF). O IQA 
abrange os seguintes parâmetros: oxigênio dissolvido (OD), demanda bioquímica de oxigênio (DBO), coliformes totais e termotolerantes, nitrogênio total, fósforo total, sólidos totais, $\mathrm{pH}$, turbidez e temperatura. A cada parâmetro é atribuído um peso, listado na Tabela 3, de acordo com sua importância relativa no cálculo do IQA, refletindo a interferência por esgotos sanitários e outros materiais orgânicos, nutrientes e sólidos.

O IQA é determinado pelo produtório ponderado dos valores obtidos para os parâmetros mencionados (Equação 1):

$$
I Q A=\prod_{i=1}^{n} q_{i}^{w_{i}}
$$

Onde:

$\mathrm{q}_{\mathrm{i}}$ : qualidade do i-ésimo parâmetro, um número entre 0 e 100, obtido da respectiva curva média de variação de qualidade, em função de sua concentração ou medida;

$\mathrm{w}_{\mathrm{i}}$ : peso correspondente ao i-ésimo parâmetro, um número entre $0 \mathrm{e}$ 1, atribuído em função da sua importância para a conformação global de qualidade, sendo que (Equação 2):

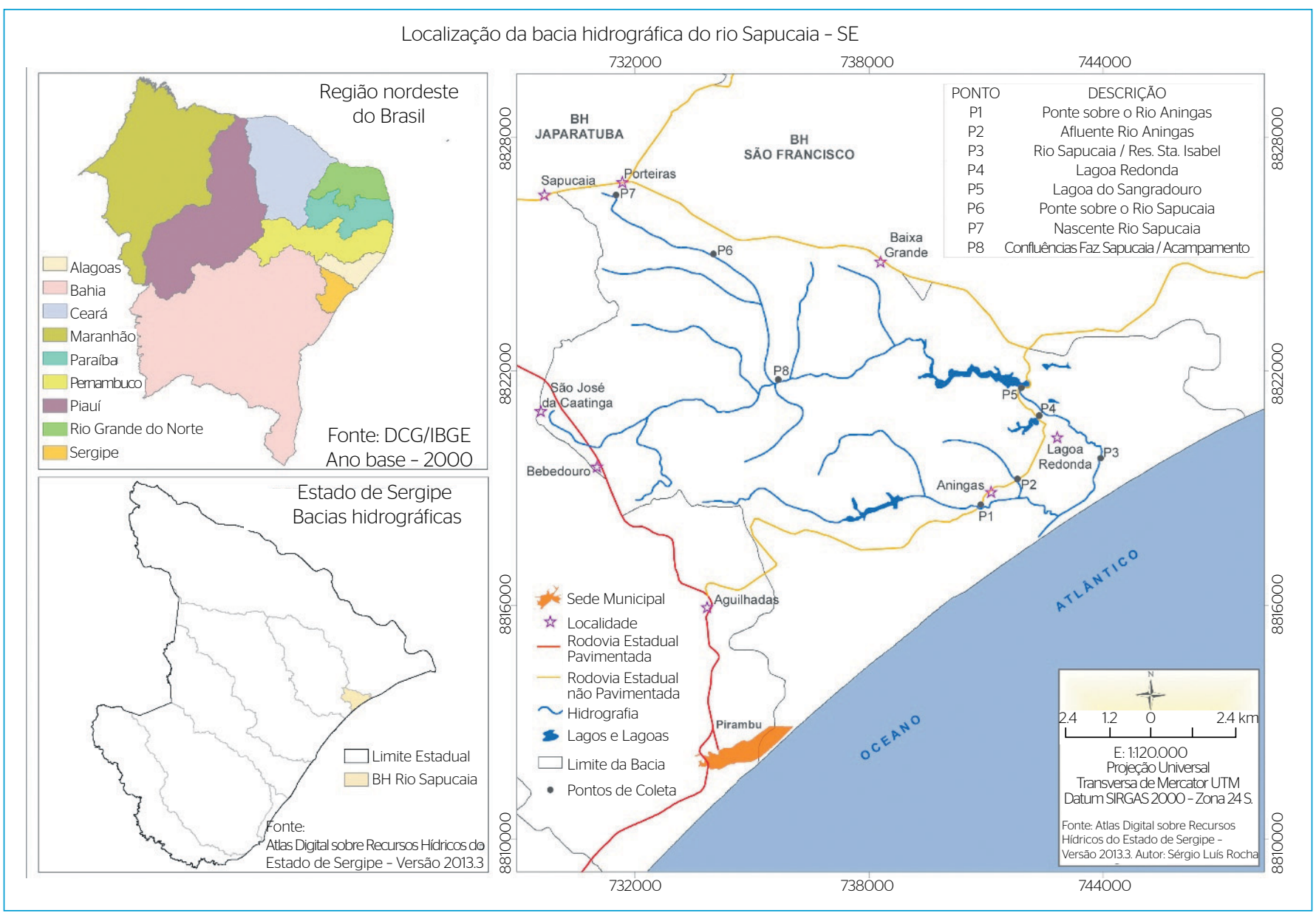

Figura 1 - Bacia Costeira do Sapucaia e pontos de coleta de água.

Tabela 1 - Identificação dos pontos de coleta e suas coordenadas geográficas.

\begin{tabular}{|c|c|c|c|c|}
\hline Código & Descrição & UTM & UTM & Altitude \\
\hline P1 & Ponte sobre o rio Aningas & $770.869 \mathrm{~W}$ & $8.881 .856 \mathrm{~S}$ & $26 \mathrm{~m}$ \\
\hline P2 & Riacho afluente do Rio Aningas & $741.808 \mathrm{~W}$ & $8.881920 \mathrm{~S}$ & $11 \mathrm{~m}$ \\
\hline P3 & Rio Sapucaia na Reserva Santa Isabel & $743.943 \mathrm{~W}$ & $8.819 .748 \mathrm{~S}$ & $15 \mathrm{~m}$ \\
\hline P4 & Lagoa Redonda & $742.367 \mathrm{~W}$ & $8.820 .840 \mathrm{~S}$ & $14 \mathrm{~m}$ \\
\hline P5 & Rio Sapucaia/Lagoa do Sandradouro & $741.907 \mathrm{~W}$ & $8.821 .568 \mathrm{~S}$ & $16 \mathrm{~m}$ \\
\hline P6 & Ponte sobre o Rio Sapucaia & $734.034 \mathrm{~W}$ & $8.824 .982 \mathrm{~S}$ & $39 \mathrm{~m}$ \\
\hline P7 & Nascente do Rio Sapucaia & $731.523 \mathrm{~W}$ & $8.826 .502 \mathrm{~S}$ & $76 m$ \\
\hline P8 & Confluência do rio Sapucaia com o Rio Aningas & $735.672 \mathrm{~W}$ & $8.821 .766 \mathrm{~S}$ & $31 \mathrm{~m}$ \\
\hline
\end{tabular}

UTM: Universal Transverse Mercator. 
$\sum_{i=1}^{n} w_{i}=1$

Onde:

n: número de parâmetros que entram no cálculo do IQA.

A partir do cálculo efetuado, determina-se a qualidade das águas, que é indicada pelo IQA, em valores que variam numa escala entre 0 e 100, conforme faixas indicadas na Tabela 4.

\section{Índice do Estado Trófico (IET)}

O IET tem por finalidade classificar corpos d'água em diferentes graus de trofia, ou seja, avaliar a qualidade da água quanto ao enriquecimento por nutrientes e seu efeito relacionado ao crescimento excessivo das algas ou ao aumento da infestação de macrófitas aquáticas (CETESB, 2009).

Adotaram-se neste estudo os cálculos do IET propostos pela CETESB (2005) e pela ANA (BRASIL, 2004), os quais estão indicados nas Equações 3 a 7 (MARQUES et al., 2014):

Cálculo para ambiente lótico

$\operatorname{IET}(\mathrm{PT})=10 \mathrm{x}(6-((0,42-0,36 \mathrm{x}(\mathrm{In} \mathrm{PT})) / \operatorname{In} 2))-20$

$\operatorname{IET}(\mathrm{CL})=10 \mathrm{x}(6-((0,70-0,6 \mathrm{x}(\mathrm{In} \mathrm{CL})) / \mathrm{In} 2))-20$

Cálculo para ambiente lêntico

$\operatorname{IET}(\mathrm{PT})=10 \mathrm{x}(6-((1,77-0,42 \times($ In PT $)) / \operatorname{In} 2))$

$\operatorname{IET}(\mathrm{CL})=10 \mathrm{x}(6-((0,92-0,34 \times($ In CL $)) /$ In 2$))$

Cálculo do IET
$\mathrm{IET}=[\mathrm{IET}(\mathrm{PT})+\mathrm{IET}(\mathrm{CL})] / 2$

Onde:

PT: concentração de fósforo total (em mg.L $\left.\mathrm{L}^{-1}\right)$;

CL: concentração de clorofila total (em mg.. $\left.\mathrm{L}^{-1}\right)$;

ln: é o logaritmo natural.

Tabela 3 - Peso relativo dos parâmetros utilizados no Índice de Qualidade de Água.

\begin{tabular}{l|c} 
Parâmetros & Peso $(\mathrm{w})$ \\
\hline Coliformes termotolerantes & 0,15 \\
\hline $\mathrm{pH}$ & 0,12 \\
\hline Demanda bioquímica de oxigênio & 0,10 \\
\hline Nitrogênio total & 0,10 \\
\hline Fósforo total & 0,10 \\
\hline Diferença de temperatura & 0,10 \\
\hline Turbidez & 0,08 \\
\hline Sólidos totais & 0,08 \\
\hline Oxigênio dissolvido & 0,17
\end{tabular}

Tabela 4 - Classificação do Índice de Qualidade de Água do acordo com os valores adotados pela Agência Nacional de Águas.

\begin{tabular}{l|c} 
Valor & Categoria \\
\hline $79<1 \mathrm{Q} A \leq 100$ & Otima \\
\hline $51<1 \mathrm{Q} A \leq 79$ & Boa \\
\hline $36<1 \mathrm{Q} A \leq 51$ & Regular \\
\hline $19<1 \mathrm{Q} A \leq 36$ & Ruim \\
\hline $1 \mathrm{Q} A \leq 19$ & Péssima \\
\hline
\end{tabular}

IQA: Indice de Qualidade de Água.

Fonte: BRASIL (2004).

Tabela 2 - Metodologia adotada para as análises dos parâmetros de qualidade de água, unidades de medidas e limite de quantificação do método.

\begin{tabular}{|c|c|c|c|}
\hline Ensaios & Métodos & Unidade & LQ \\
\hline Coliformes totais & SMEWW $9221 \mathrm{~A}$ & NMP.100 $\mathrm{mL}^{-1}$ & - \\
\hline Coliformes termotolerantes & SMEWW $9221 \mathrm{~B}$ & NMP.100 mL'-1- & - \\
\hline Demanda bioquímica de oxigênio & SWEWW 5210 D & $\mathrm{mg} \mathrm{O}_{2}$ & - \\
\hline Clorofila & SWEWW 10200 I & $\mathrm{mg} \cdot \mathrm{L}^{-1}$ & 1,000 \\
\hline Sólidos totais & SWEWW 2540 C & $\mathrm{mg} \cdot \mathrm{L}^{-1}$ & - \\
\hline Fósforo Total & SWEWW 4500 P & $m g \cdot L^{-1}$ & 0,010 \\
\hline Oxigênio dissolvido & SWEWW 45000 & $\mathrm{mg} \mathrm{O}_{2} \mathrm{~L}^{-1}$ & - \\
\hline Nitrogênio total & SWEWW 450N & $m g \cdot L^{-1}$ & - \\
\hline Turbidez & SWEWW 2130 A & UNT & - \\
\hline
\end{tabular}

LQ: Limite de Quantificação; NMP: Número Mais Provável; UNT: Unidade Nefelométrica de Turbidez.

Fonte: APHA; AWWA; WEF, 2012 
O IET é indicado por classe de trofia de acordo com as faixas de valores apresentadas na Tabela 5 (CETESB, 2009; BRASIL, 2004).

\section{RESULTADOS E DISCUSSÃO}

A estatística descritiva dos parâmetros estudados neste trabalho, bem como os limites definidos pela Resolução do Conselho Nacional de Meio Ambiente (CONAMA) nº 357/2005 para corpos d'água classe 2, estão apresentados na Tabela 6.

Os resultados das análises de $\mathrm{pH}$ apresentaram variações na faixa de 4,6 a 7,6 com média de 5,9 $\pm 0,7$, demonstrando que o $\mathrm{pH}$ dos rios da bacia é levemente ácido. Observa-se na Figura 2 que a maioria das amostras de água analisadas neste estudo apresentam o $\mathrm{pH}$ abaixo dos limites mínimos estabelecidos pela Resolução CONAMA n ${ }^{\circ}$ $357 / 2005$ para corpos de água classe 2 (6,0 a 9,0) (BRASIL, 2014). Isso se deve, provavelmente, à composição geoquímica do solo da região litorânea norte de Sergipe pois, de acordo com Maier (1978), os rios que escoam sobre formações ígneas tendem a ter um $\mathrm{pH}$ abaixo da neutralidade.

Tabela 5 - Classificação do Índice de Estado Trófico do acordo com os valores adotados pela Agência Nacional de Águas.

\begin{tabular}{l|c} 
Estado trófico & Ponderação \\
\hline Ultraoligotrófico & $\mathrm{IET} \leq 47$ \\
\hline Oligotrófico & $47<\mid \mathrm{ET} \leq 52$ \\
\hline Mesotrófico & $52<\mid \mathrm{ET} \leq 59$ \\
\hline Eutrófico & $59<\mid \mathrm{ET} \leq 63$ \\
\hline Supereutrófico & $63<\mid \mathrm{ET} \leq 67$ \\
\hline Hipereutrófico & $\mathrm{IET}>67$ \\
\hline
\end{tabular}

IET: Indice de Estado Trófico.

Fonte: CETESB (2009); BRASIL (2004).
Em estudo realizado por Marques et al. (2011), a bacia do baixo São Francisco, no estado de Sergipe, apresenta pH mínimo 7,34 e máximo 9,14, com características mais próximas ao $\mathrm{pH}$ neutro, evidenciando que, apesar da proximidade com a BCS, essas bacias apresentam diferentes padrões de $\mathrm{pH}$.

Outro resultado de monitoramento realizado por Alves et al. (2007) no período de novembro de 2005 a setembro de 2006 na bacia hidrográfica do rio Sergipe apresenta valores de $\mathrm{pH}$ variando de 5,3 a 8,7; os menores valores ocorreram na água do Rio Pitanga e os valores maiores na água do Rio Poxim. Sendo assim, pode-se dizer que esses estão com valores aproximados aos da BCS.

Ao avaliar-se o nível de OD na BCS (Figura 3), verificou-se que os valores obtidos nos 8 pontos de coleta de água apresentaram um valor mínimo de 6,04 $\mathrm{mg} \mathrm{O}_{2} \cdot \mathrm{L}^{-1}$ e um valor máximo de $8,98 \mathrm{mg} \mathrm{O} \cdot \mathrm{O}_{2}^{-1}$ (média de 7,79 $\pm 0,69 \mathrm{mg} \mathrm{O}_{2} \cdot \mathrm{L}^{-1}$ ). Essas medidas estão acima dos limites mínimos estabelecidos pela Resolução CONAMA n 357/2005, que regulamenta que os níveis de $\mathrm{OD}$ não devem ser inferiores a $5 \mathrm{mg}$ $\mathrm{O}_{2} \cdot \mathrm{L}^{-1}$ para água doce classe 2 (BRASIL, 2014).

Observa-se que somente o ponto 5 , durante os meses de novembro de 2014 e fevereiro de 2015, apresenta a concentração de OD limítrofe de $6 \mathrm{mg} \mathrm{O}_{2} \cdot \mathrm{L}^{-1}$. Isso indica que a carga orgânica recebida pelos rios da bacia está bem abaixo da sua capacidade de autodepuração, ou seja, o impacto por carga orgânica na bacia é baixo.

Estudo realizado em Sergipe, especificamente no Rio Poxim (Bacia Hidrográfica do Rio Sergipe), revelou concentrações de OD de 3,45 a $8,32 \mathrm{mg} . \mathrm{L}^{-1}$ no período seco e de 4,98 a 7,11 mg.L $\mathrm{L}^{-1}$ no período chuvoso (VASCO et al., 2011). Em outro estudo realizado no Rio PoximAçu, no período de novembro de 2005 a setembro de 2006, os valores de OD ficaram abaixo de $4 \mathrm{mg} . \mathrm{L}^{-1} \mathrm{e}$ atingiram níveis inferiores a $2 \mathrm{mg}$. $\mathrm{L}^{-1}$. A situação crítica do Rio Poxim-Açu, em consequência do

Tabela 6 - Estatística descritiva dos parâmetros avaliados nas amostras de água, bem como os limites estabelecidos pela Resolução do Conselho Nacional de Meio Ambiente no 357/2005.

\begin{tabular}{|c|c|c|c|c|c|}
\hline Parâmetros avaliados & Média & Desvio padrão & Valor mínimo & Valor máximo & CONAMA n $357 / 2005$ Classe 2 \\
\hline Demanda bioquímica de oxigênio (mg. $\left.\mathrm{L}^{-1}\right)$ & 2,81 & 2,73 & nd & 8,05 & 5,00 \\
\hline Coliformes termotolerantes (NMP.100 mL'-1) & 474 & 532 & 12 & 2.800 & 1.000 \\
\hline Coliformes totais (NMP.100 mL-1) & 7.469 & 11.410 & 110 & 36.000 & \\
\hline Fósforo total (mg.L'1) & 0,06 & 0,17 & nd & 0,54 & 0,10 \\
\hline Nitrogênio total (mg.L'1) & 0,19 & 0,29 & nd & 1,07 & \\
\hline Oxigênio dissolvido $\left(\mathrm{mg} \mathrm{O}_{2} \mathrm{~L}^{-1}\right)$ & 7,79 & 0,69 & 6,04 & 8,98 & 5,00 \\
\hline $\mathrm{pH}$ & 5,88 & 0,69 & 4,60 & 7,60 & 6,00 a 9,00 \\
\hline Turbidez (UNT) & 3,89 & 3,51 & 0,03 & 10,10 & 100,00 \\
\hline Temperatura $\left({ }^{\circ} \mathrm{C}\right)$ & 25,49 & 1,92 & 22,70 & 29,70 & \\
\hline Condutividade $\left(\mu \mathrm{S} . \mathrm{cm}^{-1}\right)$ & $1.909,31$ & $2.749,74$ & 39,00 & $7.058,00$ & \\
\hline Sólidos totais (mg. L $^{-1}$ ) & 563,45 & 594,47 & 20,00 & $1.840,00$ & \\
\hline Clorofila $\left(\mu \mathrm{g} . \mathrm{L}^{-1}\right)$ & 4,20 & 3,83 & 0,42 & 21,98 & 30,00 \\
\hline
\end{tabular}

CONAMA: Conselho Nacional de Meio Ambiente; NMP: Número Mais Provável; UNT: Unidade Nefelométrica de Turbidez; nd: não detectado; n: 40 amostras. 


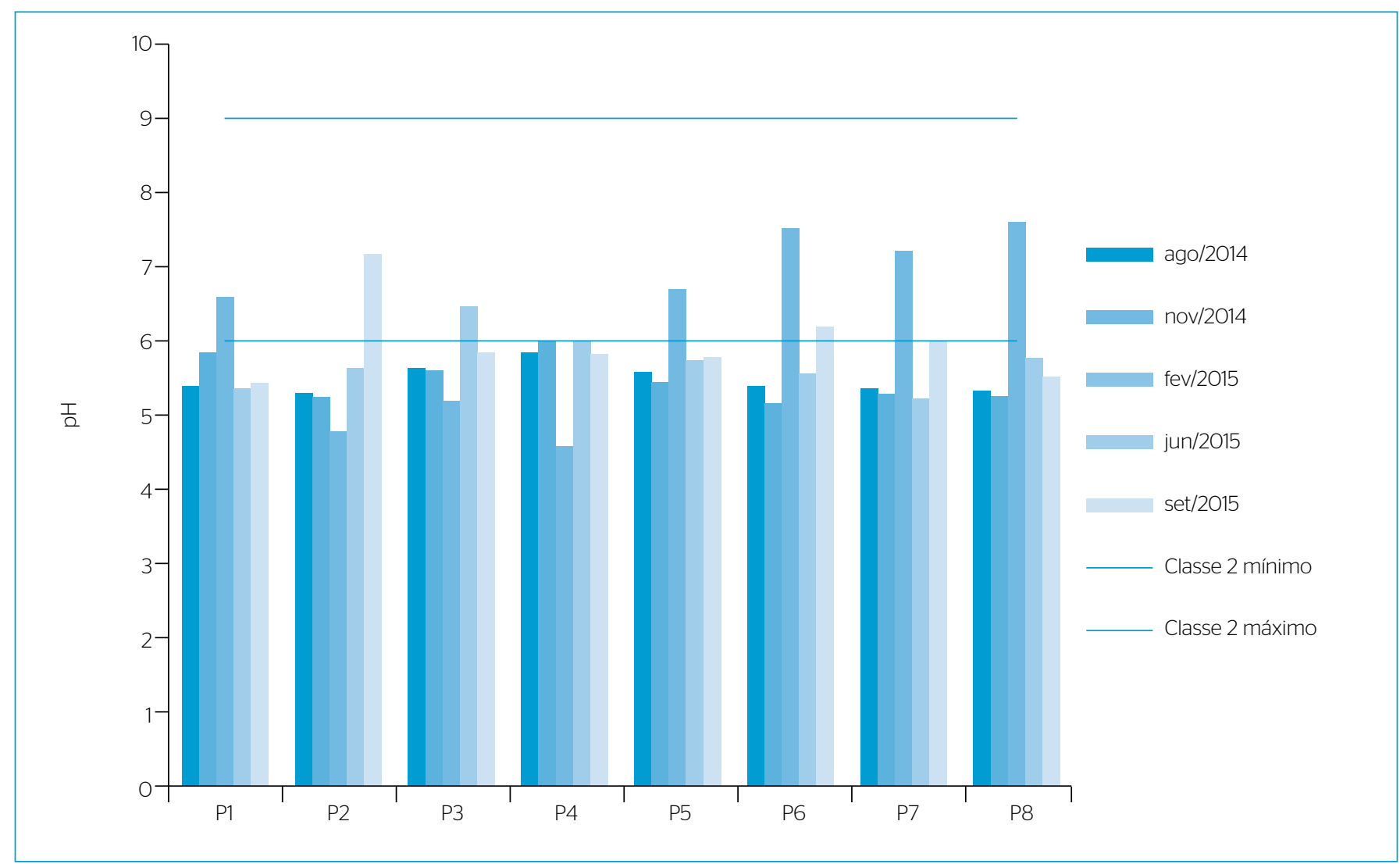

Figura 2 - Variação temporal e espacial dos valores de pH das amostras de água analisadas.

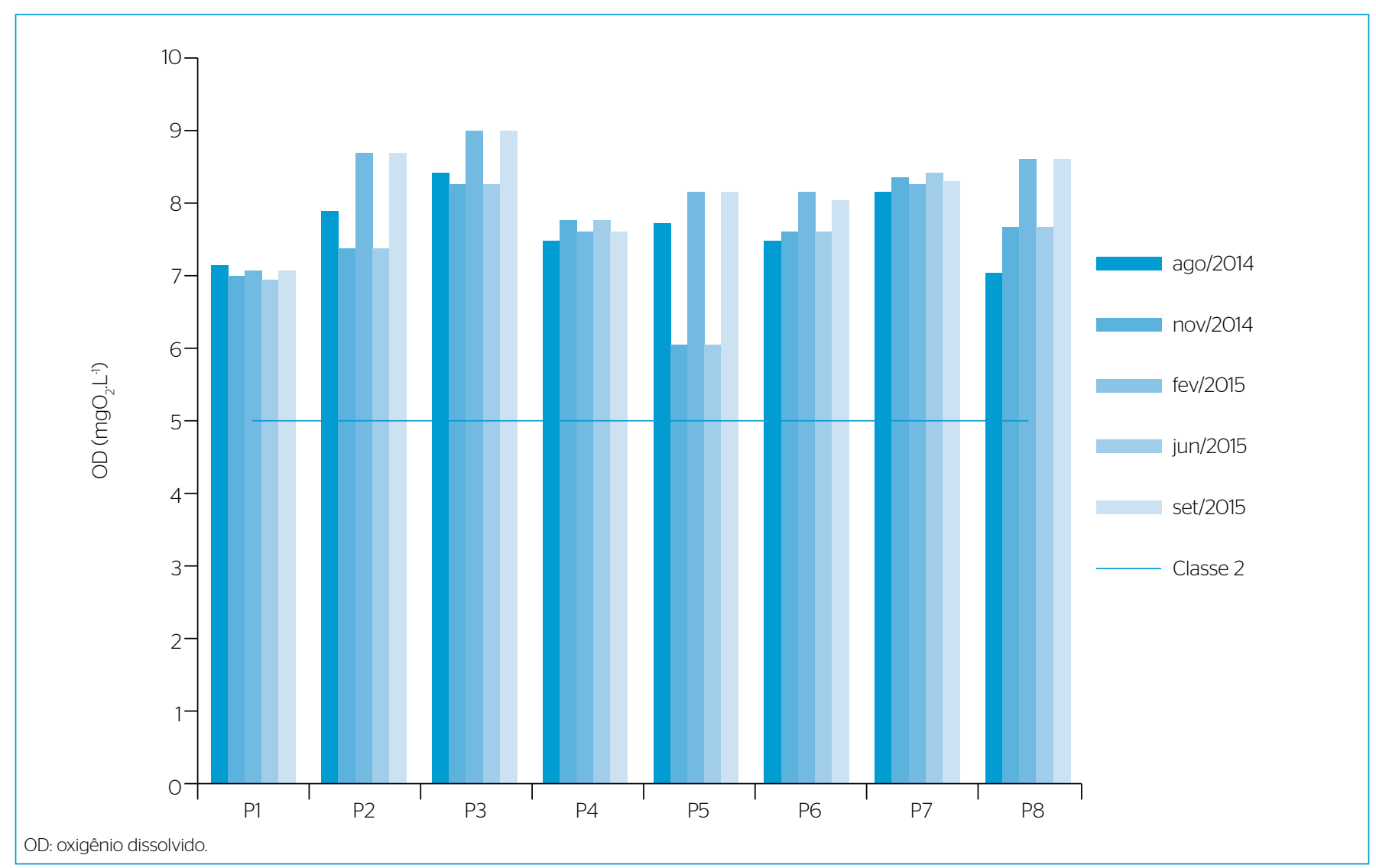

Figura 3 - Variação temporal e espacial dos valores de oxigênio dissolvido das amostras de água analisadas. 
aporte dos efluentes urbanos e/ou industriais da região urbana adjacente (ALVES et al., 2007), demonstra a importância do monitoramento sazonal da qualidade de água de outras bacias hidrográficas do estado de Sergipe.

Quanto ao fósforo, de acordo com a Resolução CONAMA n ${ }^{\circ}$ $357 / 2005$, o limite total em água classe 2 é de $0,10 \mathrm{mg}$. $\mathrm{L}^{-1}$. Os resultados das análises demonstram que, em todas as amostras do mês de setembro de 2015 e as dos pontos P2 e P3 de novembro de 2014, a presença de fósforo ultrapassa o limite permitido pela legislação (Figura 4). Verifica-se ainda que, dentro da faixa de variação detectada, os níveis de fósforo total atingem até $0,54 \mathrm{mg} . \mathrm{L}^{-1}$ com média de 0,06 $\pm 0,17$ mg.L $\mathrm{L}^{-1}$ (Tabela 6).

Marques et al. (2011), em seu estudo sobre a avaliação temporal na bacia do baixo São Francisco, no estado de Sergipe, encontraram o valor mínimo de fósforo total de $0,054 \mathrm{mg}^{-\mathrm{L}^{-1}}$ e o máximo de $0,920 \mathrm{mg} . \mathrm{L}^{-1}$, indicando a presença de valores acima do limite da Resolução CONAMA n 357/2005. Já Vasco et al. (2011), nos estudos do Rio Poxim, assinalaram que foram encontrados valores de fósforo total que variaram entre 0,076 e $0,176 \mathrm{mg} . \mathrm{L}^{-1}$ durante o período chuvoso. No período seco, as concentrações de fósforo total ficaram abaixo do limite de detecção do método utilizado.
Destarte, o fato dos valores de fósforo total apresentarem-se acima do permitido pela Resolução CONAMA n 357/2005 para todos os pontos no mês de setembro de 2015 e nos pontos 2 e 3 no mês de novembro de 2014 pode ser explicado pela presença da atividade agrícola canavieira na BCS e em seu entorno. Nessa atividade, é comum o uso de fertilizantes químicos, que contêm em sua composição uma considerável proporção de fósforo, facilmente carreado pelas águas pluviais ao leito dos córregos e rios, contribuindo para o processo de eutrofização dos corpos hídricos.

Os resultados das concentrações de DBO (Figura 5) exibiram valores abaixo de $5 \mathrm{mg} . \mathrm{L}^{-1}$ em todos os meses de coletas na BCS, exceto para fevereiro de 2015. Os valores das concentrações de DBO encontrados apresentaram uma média de 2,81 $\pm 2,73 \mathrm{mg} . \mathrm{L}^{-1}$, dentro do limite permitido pela Resolução no 357/2005 do CONAMA para corpos de água doce classe 2. O aumento excessivo das concentrações de DBO em um corpo hídrico é normalmente causado por insumos de materiais variados de origem predominantemente orgânica.

O aumento da concentração de $\mathrm{DBO}$ em todos os pontos de coleta do mês de fevereiro de 2014 na BCS deve-se, provavelmente, à baixa pluviosidade e à alta taxa de evaporação devido ao aumento da temperatura e à alta incidência solar da região durante o verão (Figura 5).

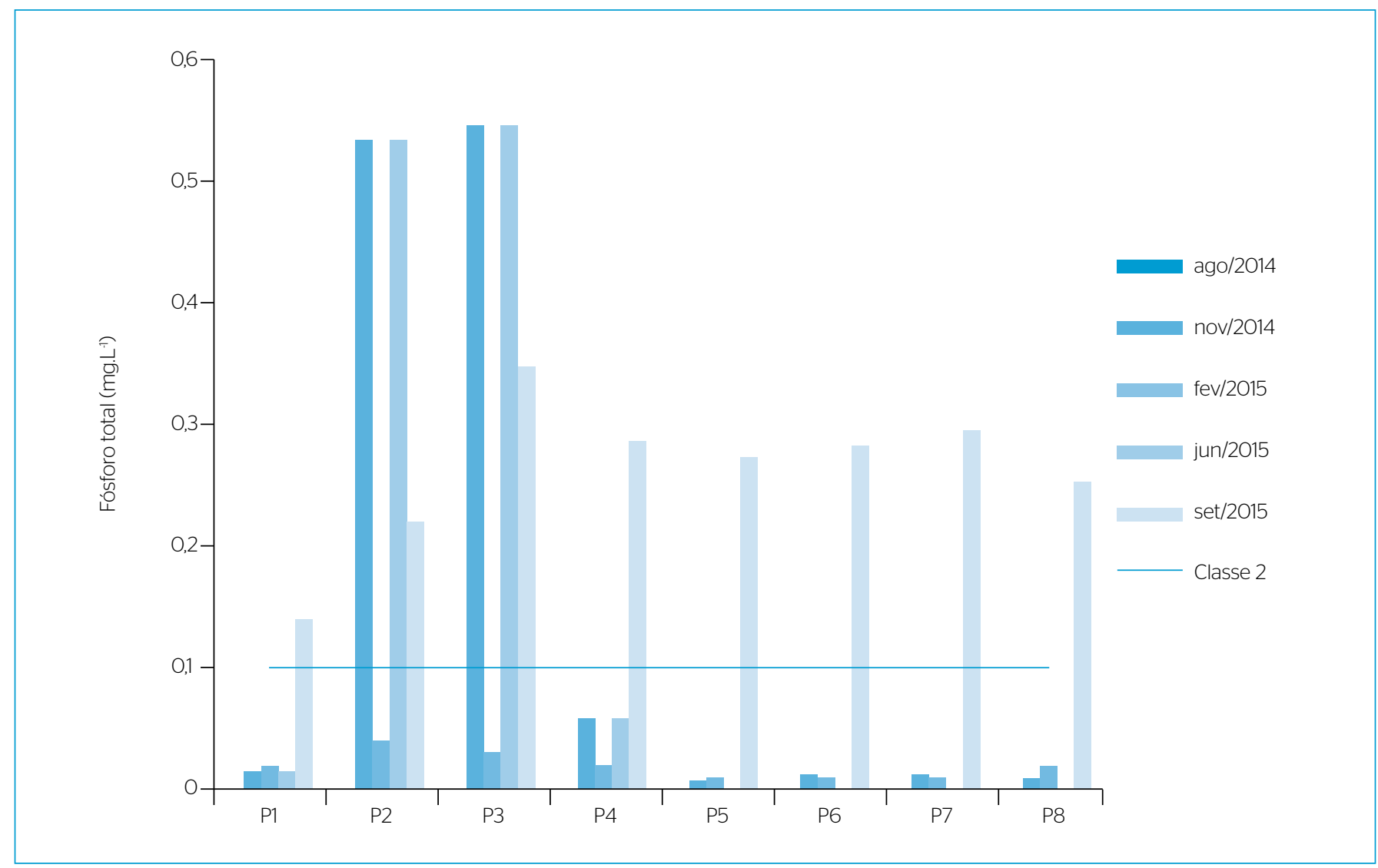

Figura 4 - Variação temporal e espacial dos valores de fósforo total das amostras de água analisadas. 
Em estudos desenvolvidos por Vasco et al. (2011) são apresentados valores entre 21,2 e 29,8 mg. $\mathrm{L}^{-1}$ nas concentrações de DBO na sub-bacia hidrográfica do Rio Poxim, em Sergipe. Marques et al. (2011) monitoraram a bacia hidrográfica do Rio São Francisco e, na altura do Rio Jacaré, município de Poço Redondo, os valores de DBO obtidos foram os mais altos, variando entre 4,90 e 110,00 mg.L $\mathrm{L}^{-1}$ (média

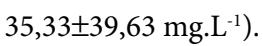

A Resolução CONAMA n 357/2005 determina que a faixa de concentração de coliformes termotolerantes para águas de classe 2 deve ser menor do que 1.000 Número Mais Provável (NMP).100 mL $\mathrm{mL}^{-1}$ (BRASIL, 2005). Somente as amostras coletadas em agosto de 2014 no ponto P5 e em junho de 2015 no P7 apresentaram valores acima do permitido (Figura 6). Esse fato pode ser explicado pela presença de animais às margens dos rios e aglomerações de pessoas nos finais de semana e feriados em uma área de lazer desprovida de saneamento básico, a montante do ponto de coleta, ressaltando ainda que essas coletas foram feitas no período de cheia (Tabela 6).

Moragas (2005) afirma que, quando se faz a análise da água e se detecta contaminação por coliformes termotolerantes, significa que naquele local houve descarga de esgoto em período recente, o que aumenta a possibilidade de haver ali organismos patogênicos intestinais, visto que esses podem ser eliminados com as fezes, ocasionando doenças de veiculação hídrica.

Também se analisou o nitrogênio total, e seus valores nas amostras de água variaram de não detectado a 1,07 mg.L-1 (média de 0,19 $\left.\pm 0,29 \mathrm{mg} . \mathrm{L}^{-1}\right)$. Duas amostras do ponto P3 apresentaram concentrações de nitrogênio total acima de 1,00 mg. $\mathrm{L}^{-1}$ nos meses de novembro de 2014 e junho de 2015 (Figura 7). Esse ponto está a jusante de uma área onde existem vários bares bastante frequentados nos finais de semana e utilizada como acesso às praias da Reserva Santa Isabel.

Em estudos de monitoramento da sub-bacia hidrográfica do Rio Poxim por Vasco et al. (2011), foram observados valores de nitrogênio total de 2,5 a 9,12 mg. $\mathrm{L}^{-1}$ e 5,7 a 49,2 mg.. $\mathrm{L}^{-1}$ nos rios Poxim-Mirim e Poxim-Açu, respectivamente. Esses valores indicam comprometimento da água, havendo quantidades de nutrientes por fontes de esgoto e pontos difusos na área, estimulando o crescimento do fitoplâncton.

Quanto à turbidez, a Resolução CONAMA nº 357/2005 estabelece um valor máximo de cem unidades nefelométricas de turbidez (UNT) para corpos de água classe 2 . A turbidez de todas as amostras coletadas está abaixo desse limite (Figura 8), sendo que as amostras analisadas

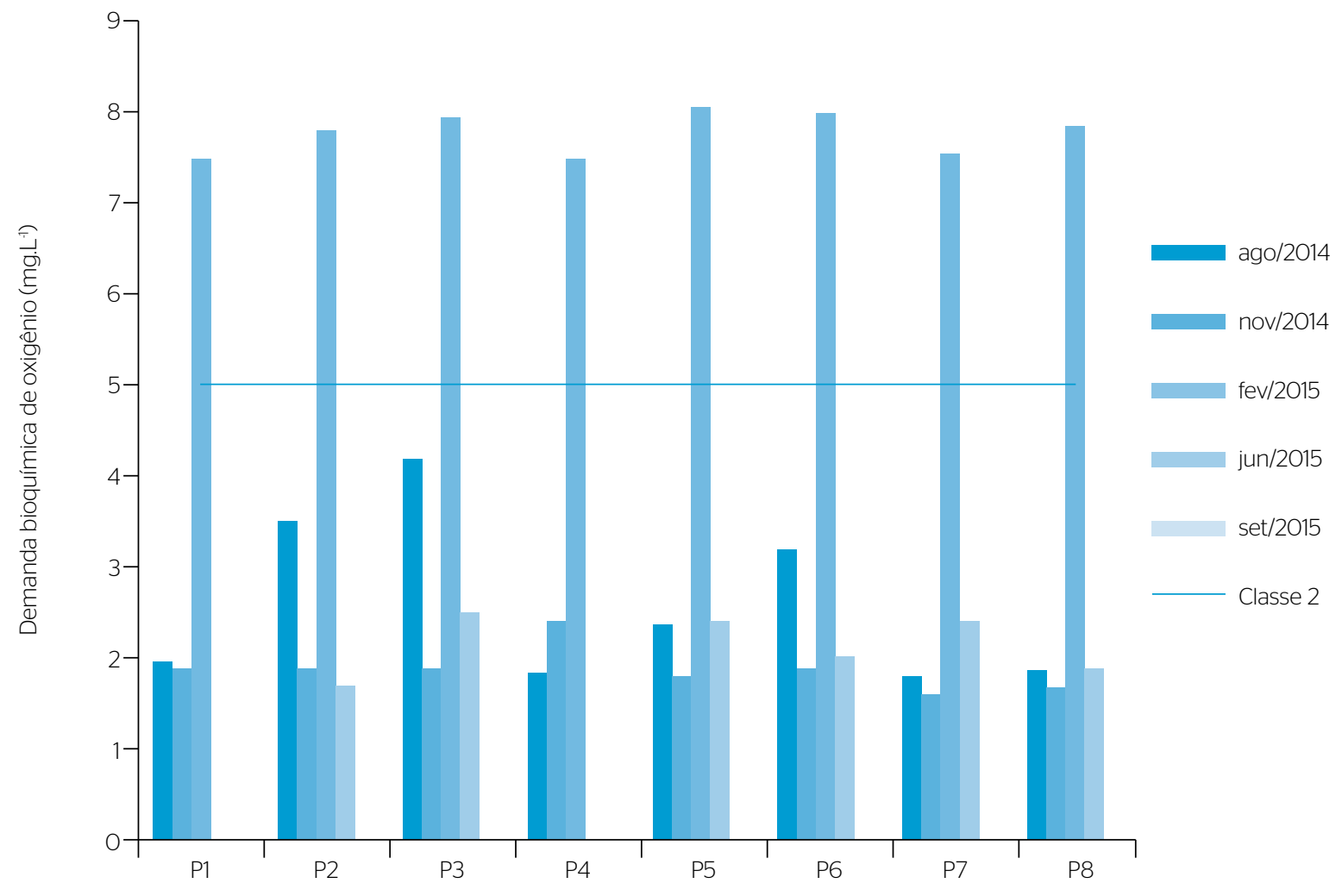

DBO: demanda bioquímica de oxigênio.

Figura 5 - Variação temporal e espacial dos valores de demanda bioquímica de oxigênio das amostras de água analisadas. 


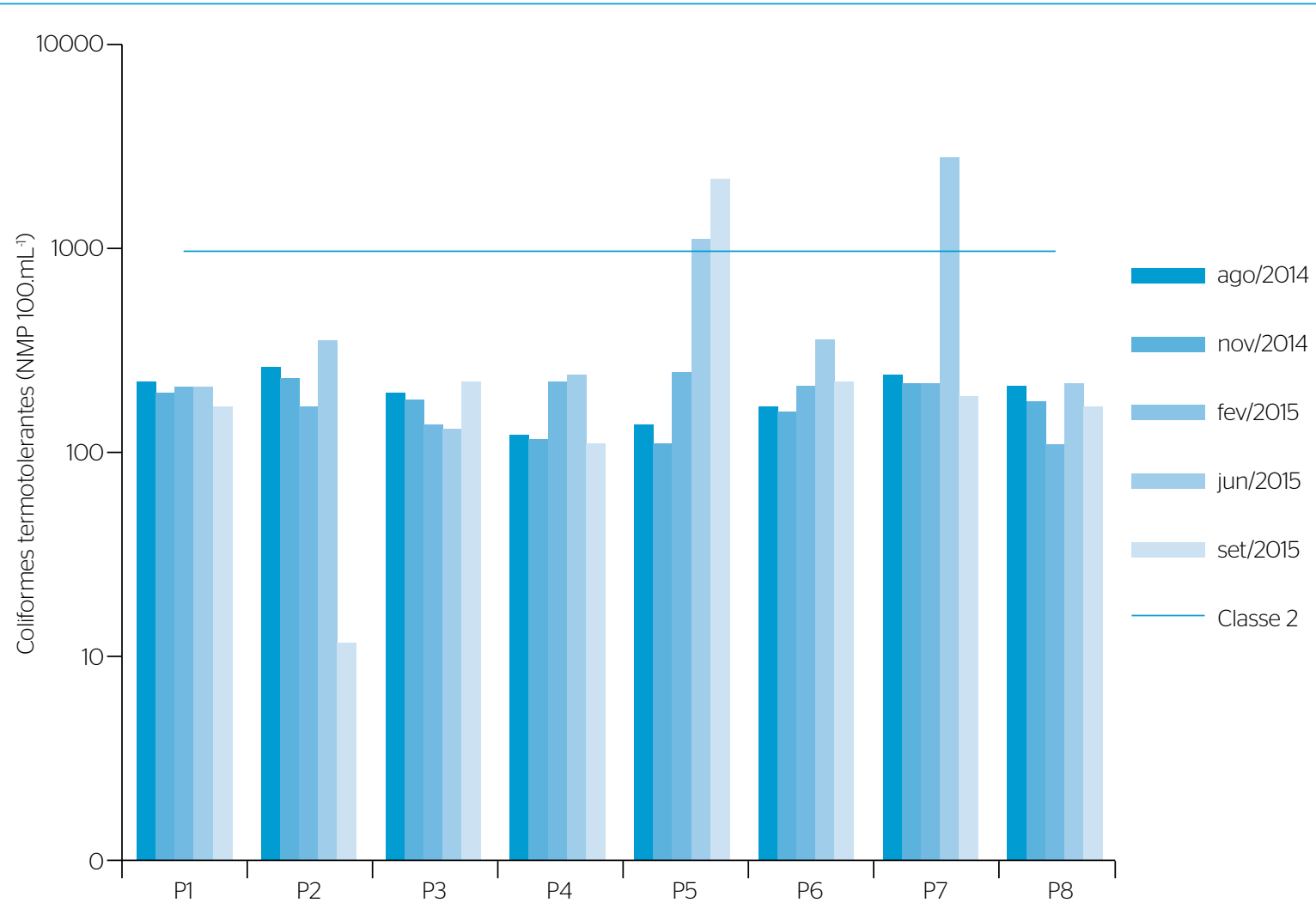

NMP: Número Mais Provável.

Figura 6 - Variação temporal e espacial dos valores de coliformes termotolerantes das amostras de água analisadas.

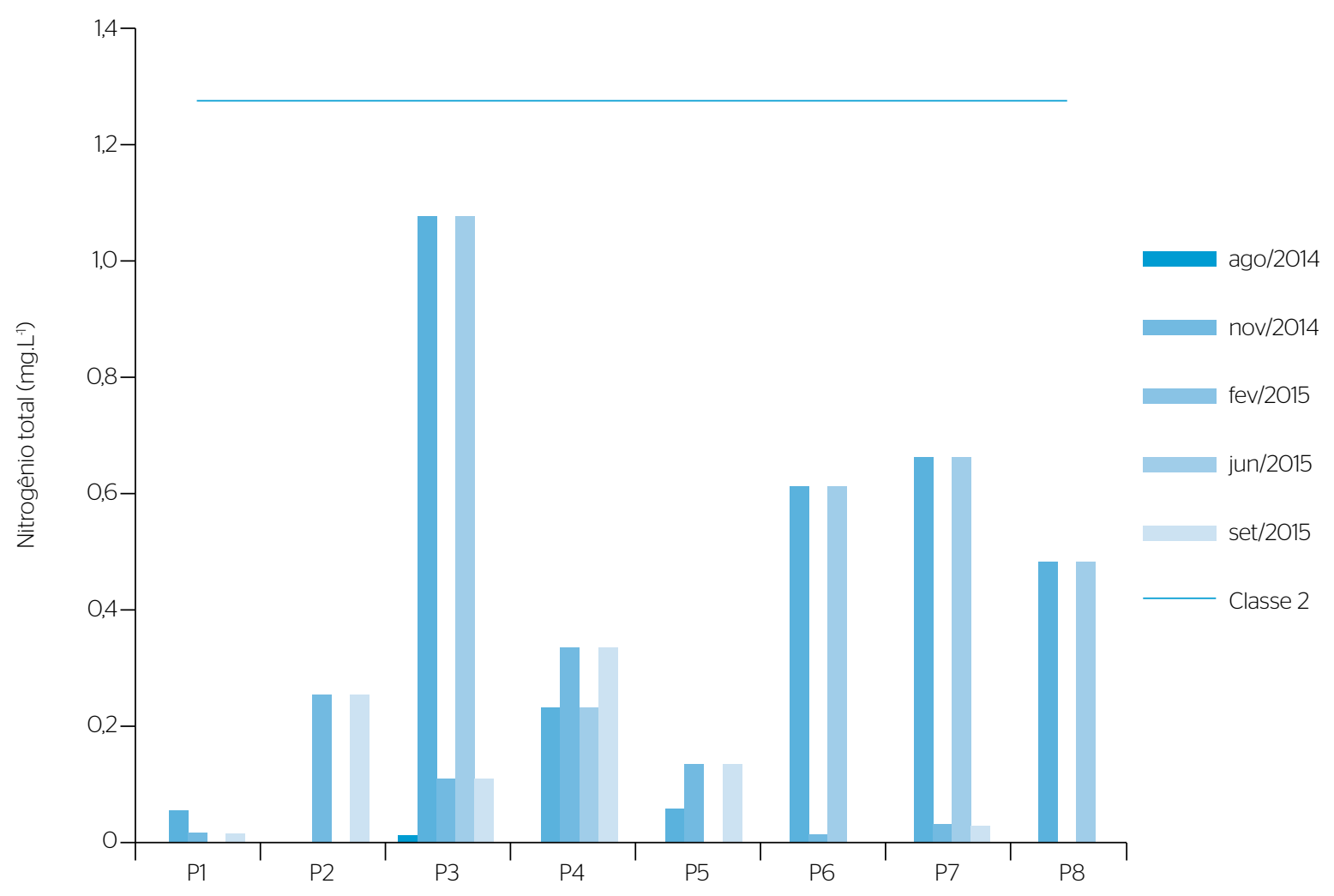

Figura 7 - Variação temporal e espacial dos valores de nitrogênio total das amostras de água analisadas. 
da BCS apresentaram valores entre 0,03 e 10,10 UNT (média 3,89 \$3,51 UNT). Gonçalves et al. (2015), ao monitorar a sub-bacia do Rio Siriri, em Sergipe, também observaram valores de turbidez que não ultrapassaram os limites da Resolução CONAMA no 357/2005.

Ainda em Sergipe, em estudo sobre a qualidade da água do Rio Poxim, percebe-se que existe uma semelhança entre valores mínimos de turbidez de 0,1 UNT, porém, com os valores máximos variando de 157,0 a 179,0 UNT, sendo esses acima do estabelecido pela Resolução CONAMA n 357/2005 para água doce classe 2 (VASCO et al., 2011).

As análises das amostras de água da BCS, em relação aos sólidos totais, apresentam valor mínimo de 20,00 mg.L-1 e máximo de $1.840,00 \mathrm{mg}$. L ${ }^{-1}$ (média de 563,45 $\pm 594,47 \mathrm{mg} . \mathrm{L}^{-1}$ ) (Figura 9). De acordo com Santos e Moraes (2012), a entrada de sólidos nas águas pode ocorrer de forma natural por meio dos processos erosivos, organismos e detritos orgânicos ou de forma antrópica pelo lançamento de lixo e esgoto, ou ainda pelo uso do solo no entorno. A Resolução CONAMA n 357/2005 não estabelece limites para sólidos totais, porém, menciona limites para sólidos dissolvidos e em suspensão, sendo de 500 e $100 \mathrm{mg} . \mathrm{L}^{-1}$ para corpos de água doce classes 2 e 1, respectivamente.
Os valores das análises de clorofila na BCS variaram na faixa de

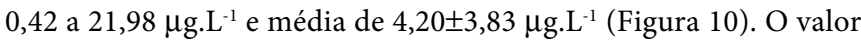
máximo permitido na Resolução CONAMA nº 357/2005 para clorofila em água doce classe 2 é de $30 \mu \mathrm{g} . \mathrm{L}^{-1}$. Um dos problemas identificados na determinação da clorofila é que esse pigmento varia na célula fitoplanctônica conforme o estado fisiológico e a espécie (KURODA et al., 2005).

\section{Aplicação de Índices para Avaliação da Qualidade da Água}

Os índices desempenham importante papel no processo de tradução dos resultados por serem facilmente compreendidos. Entretanto, os resultados podem sofrer alterações na qualidade da água e variam de acordo com o clima, com as características físicas e biológicas dos ecossistemas correspondentes, devido à contínua e constante interação entre a litosfera, a biosfera e a atmosfera. Esses processos ocorrem naturalmente, a partir da precipitação pluviométrica, que proporciona o escoamento superficial, responsável pelo carreamento em direção aos cursos d'água da bacia, do material particulado gerado a partir do impacto da gota de chuva no solo e dos íons oriundos da dissolução das rochas, além de carbono orgânico e compostos nitrogenados.

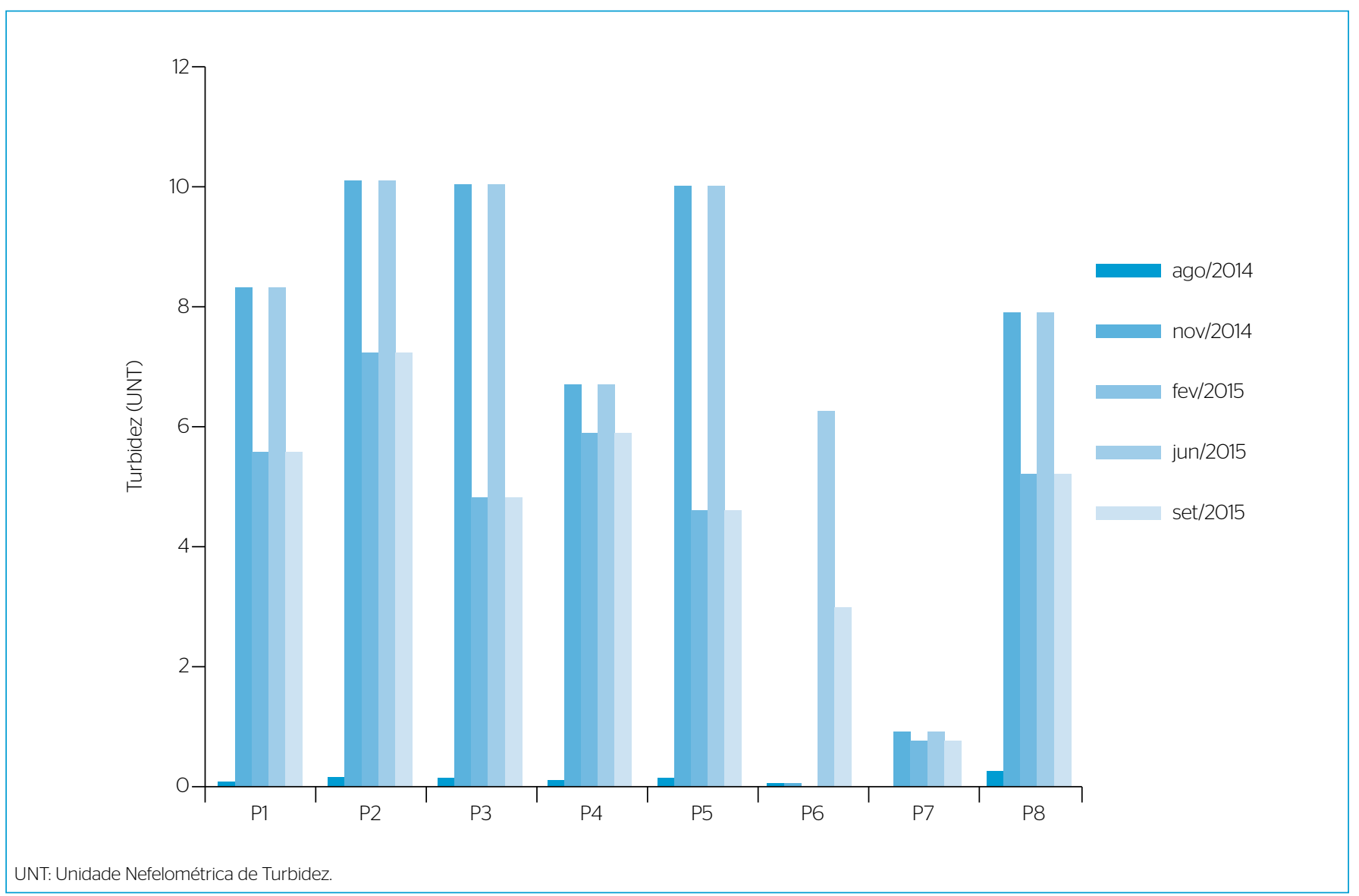

Figura 8 - Variação temporal e espacial dos valores de turbidez das amostras de água analisadas. 


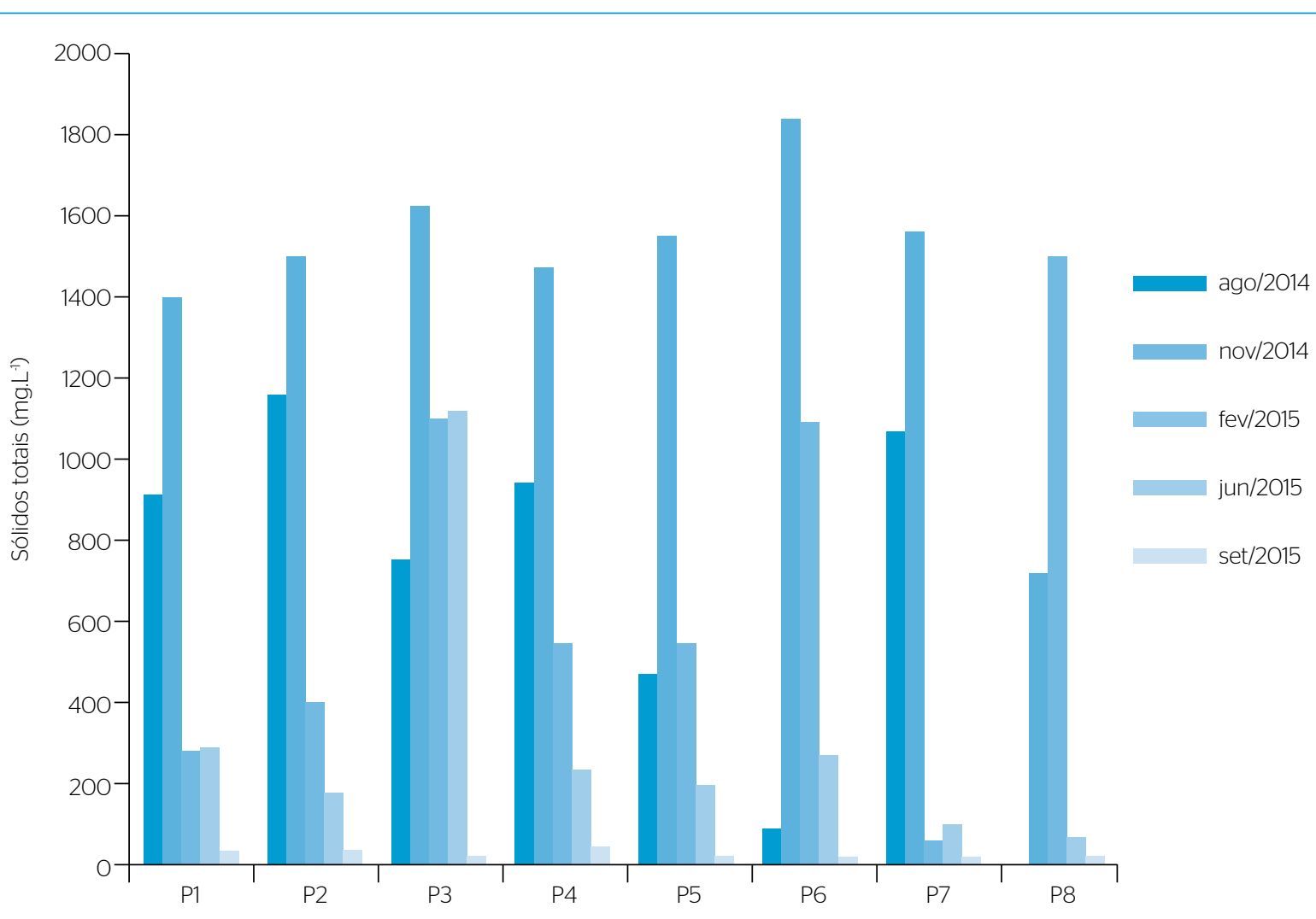

Figura 9 - Variação temporal e espacial dos valores de sólidos totais das amostras de água analisadas.

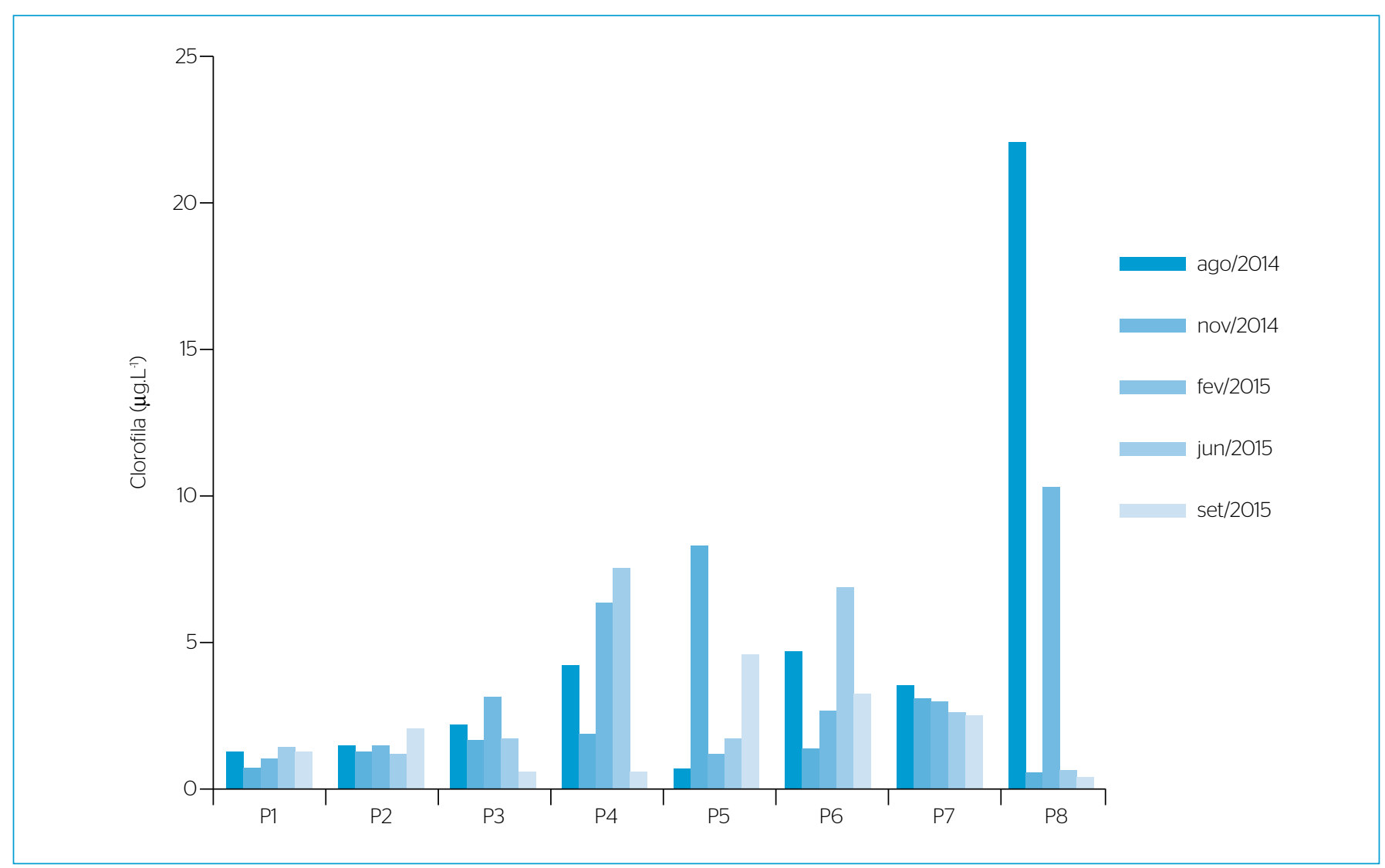

Figura 10 - Variação temporal e espacial dos valores de clorofila a das amostras de água analisadas. 
Outro processo que interfere na qualidade da água é o crescimento, a morte e a degeneração de plantas aquáticas, que tendem a alterar os teores de nitrogênio, fósforo, $\mathrm{pH}, \mathrm{OD}$, além de outros elementos sensíveis aos processos de oxirredução da matéria orgânica e oxidação da matéria orgânica nos recursos hídricos.

\section{Índice de Qualidade da Água da Bacia Costeira do Sapucaia}

Os valores obtidos nos cálculos do IQA são apresentados na Tabela 7 e classificam a água da bacia em aceitável, boa e ótima. Das 40 amostras avaliadas, 2,5\% obtiveram o índice aceitável, 92,5\% foram classificadas como boas e 5,0\% classificadas como ótimas. De maneira geral, a qualidade da água da BCS pode ser classificada como boa, e os fatores que influenciaram negativamente para que essa classificação não atingisse a categoria de ótima foram o $\mathrm{pH}$ e a presença de coliformes termotolerantes.

Os fatores que influenciaram para que a qualidade da amostra coletada no ponto P2 em junho de 2015 fosse classificada como aceitável foram: $\mathrm{pH}$, presença de coliformes termotolerantes e alta turbidez. Essa classificação também é influenciada pelo período de cheia, que durante as chuvas carreia os sedimentos e efluentes de montante a jusante do rio. $\mathrm{O}$ ponto $\mathrm{P} 2$ se localiza próximo à área urbana do povoado Aningas, e essa não possui saneamento básico, evidenciando a contaminação por fontes difusas no período chuvoso, associada ao escoamento superficial pela ação das enxurradas.

Os resultados do IQA do ponto P5 são corroborados pelos resultados obtidos no monitoramento realizado pelo estado de Sergipe, que tem um ponto de monitoramento no Rio Sapucaia. O período de monitoramento no Rio Supacaia foi de junho de 2013 a janeiro de 2014, e apresentou como resultados no período chuvoso o valor do IQA igual a 78 e, no seco, o valor de IQA igual a 65, classificando a água desse rio como boa (MACEDO et al., 2014).

Resultados semelhantes para outras bacias no estado são apresentados por Marques et al. (2011) utilizando a metodologia IQA, adotada pela ANA, entre os meses de novembro de 2008 a novembro de 2010, classificando os cursos de águas da bacia do Rio Japaratuba como aceitável e boa; e da bacia do Rio São Francisco como péssima, boa e excelente. Essas bacias fazem parte da unidade de planejamento dos recursos hídricos do estado de Sergipe.

\section{Índice do Estado Trófico da Bacia Costeira do Sapucaia}

O IET foi estimado segundo propostas de Lamparelli (2004), utilizando-as equações 3 e 4, que calculam os índices relativos ao fósforo total e à clorofila, respectivamente, em ambientes lóticos. O índice final é calculado pela média aritmética desses dois índices, representada na Equação 7. Os resultados dos cálculos estão apresentados na Tabela 8. Desses, $67,5 \%$ foram classificados como ultraoligotróficos, 20,0\% como oligotróficos, 2,5\% como mesotróficos, 7,5\% como eutróficos e 2,5\% como supereutróficos.

O IET geral calculado em todos os pontos foi considerado como ultraoligotrófico nas campanhas dos meses de agosto e novembro de 2014 e fevereiro de 2015, apresentando valores IET $\leq 52$; foi considerado predominantemente oligotrófico na campanha de junho

Tabela 7 - Valores de Índice de Qualidade de Água obtido para as amostras de água da Bacia Costeira do Sapucaia.

\begin{tabular}{|c|c|c|c|c|c|c|c|c|}
\hline Período & P1 & P2 & P3 & P4 & P5 & P6 & P7 & P8 \\
\hline Ago/2014 & 65 & 63 & 66 & 76 & 69 & 70 & 71 & 69 \\
\hline Nov/2O14 & 68 & 65 & 68 & 76 & 68 & 70 & 70 & 65 \\
\hline Jun/2015 & 66 & 50 & 65 & 72 & 59 & 67 & 62 & 67 \\
\hline Set/2015 & 70 & 83 & 68 & 70 & 61 & 70 & 70 & 68 \\
\hline
\end{tabular}

Tabela 8 - Resultados do Índice de Estado Trófico das Campanhas da Bacia Costeira do Sapucaia.

\begin{tabular}{|c|c|c|c|c|c|c|c|c|}
\hline Meses & P1 & $\mathrm{P} 2$ & P3 & P4 & P5 & P6 & P7 & P8 \\
\hline Ago/2014 & 38 & 39 & 41 & 46 & 36 & 44 & 45 & 45 \\
\hline Nov/2014 & 38 & 49 & 50 & 47 & 45 & 40 & 47 & 45 \\
\hline Fev/2015 & 40 & 43 & 46 & 48 & 39 & 46 & 46 & 49 \\
\hline Jun/2015 & 48 & 49 & 64 & 50 & 40 & 45 & 45 & 45 \\
\hline \multirow[t]{2}{*}{ Set/2015 } & 46 & 49 & 45 & 46 & 53 & 63 & 63 & 63 \\
\hline & $\begin{array}{l}\text { Ultraoligotrófico } \\
\leq 47\end{array}$ & $\begin{array}{c}\text { Oligotrófico } \\
47<1 E T \leq 52\end{array}$ & $\begin{array}{c}\text { Mesotrófico } \\
52<\mid E T \leq 59\end{array}$ & $\begin{array}{c}\text { Eutrófico } \\
59<1 E T \leq 63\end{array}$ & $\begin{array}{c}\text { Supertrófico } \\
63<1 E T \leq 67\end{array}$ & $\begin{array}{c}\text { Hipertrófico } \\
>67\end{array}$ & & \\
\hline
\end{tabular}


de 2015, com valores variando entre 40 e 64; como predominantemente eutrófico na campanha do mês de setembro de 2015, com valores entre 45 e 63 (Tabela 8). As campanhas de junho e setembro de 2015 apresentaram, para os pontos P3, P6, P7 e P8, resultados altos para o IET.

Os resultados obtidos permitem dizer que o comportamento do IET ao longo da BCS é estável, ponderando quanto à ocorrência de períodos em que os valores alcançados tornam-se críticos, principalmente para a deterioração na qualidade da água, devido às características do entorno dos corpos d'água dessa bacia.

A elevação no valor do IET nos pontos P3, P6, P7 e P8 pode ser justificada pelo fato de que no ponto de coleta $\mathrm{P} 3$ existem bares sem saneamento às margens do rio e nos finais de semana e feriados ocorre a utilização da área para o lazer. Os pontos P6 e P7 ficam próximos às aglomerações urbanas e, próximo ao ponto de coleta P8, localizam-se granjas de criação de aves, casas de assentamento também desprovidas de saneamento básico, área de pastagem com presença de animais e utilização do local para lavagens de roupas e utensílios domésticos.

\section{CONCLUSÃO}

O monitoramento das águas superficiais da BCS em Sergipe mostrou que os corpos d'água ainda não estão sofrendo processos intensos de degradação, o que é apontado por 37 amostras que apresentaram qualidade boa e 2 com qualidade ótima. Somente uma amostra obteve qualidade aceitável, em ponto de coleta situado próximo à área urbana, e a amostra foi coletada no período de cheia.

Os parâmetros de qualidade da água, avaliados dentro do contexto da BCS para o IQA e o IET, apontam que as fontes de contaminação antrópica ainda são incipientes e provavelmente contribuirão em longo prazo para o processo de degradação e eutrofização dos corpos d'água, que atualmente apresentam águas de boa qualidade.

Em resumo, a análise conjunta das concentrações obtidas dos parâmetros, para os pontos amostrais adotados, permite afirmar que os rios Aningas, Sapucaia e a Lagoa Redonda, da BCS, em Sergipe, apresentam baixo grau de degradação, com maior comprometimento do ponto amostral P3, por ser localizado em uma área bastante visitada nos finais de semana e feriados.

Existem poucos registros de estudos da qualidade da água nesse ecossistema aquático. Assim, este trabalho pode contribuir para a melhoria da qualidade da água e transmitir de forma clara e simples as características da água da BCS. Desse modo, as informações e os estudos da BCS podem ser usados como subsídios para ações pedagógicas nos mais diversos níveis de conhecimento. Podem ainda contribuir no gerenciamento dos recursos hídricos, não se restringindo apenas aos gestores envolvidos com a bacia, mas também a qualquer pessoa interessada em desenvolver ações que visem à preservação e à gestão das águas.

\section{REFERÊNCIAS}

ALVES, J.P.H.; GARCIA, C.A.B.; AGUIAR NETTO, A.O.; FERREIRA, R.A.; SANTOS, D.B.; BEZERRA, D.S.S.; BARBOSA, C.D.E.S.; COSTA, A.S. (2007) Rio Poxim qualidade da água e suas variações sazonais. In: Simpósio Brasileiro de Recursos Hídricos, 17. Anais... São Paulo.

AMERICAN PUBLIC HEALTH ASSOCIATION; AMERICAN WATER WORKS ASSOCIATION; WATER ENVIRONMENT FEDERATION APHA; AWWA; WEF. (2012) Standard Methods for the Examination of Water and Wastewater. Washington DC, Estados Unidos: APHA/AWWA/WEF.

BRASIL. (2005) Ministério do Meio Ambiente. Conselho Nacional do Meio Ambiente (CONAMA). Resolução n.o 357. Diário Oficial da União, Brasília. Disponível em: <http://www. mma.gov.br/port/conama/res/res86/res2086.html>. Acesso em: 20 ago. 2015

BRASIL. (2011) Ministério do Meio Ambiente. Instituto Chico Mendes de Conservação da Biodiversidade (ICMBio). Ciranda das Águas. Brasília. Disponível em: <http://www.icmbio.gov.br/ educacaoambiental/images/stories/biblioteca/rio_20/Ciranda_das Águas.pdf>. Acesso em 15. out. 2015.
BRASIL. (2014) Ministério das Cidades. Secretaria Nacional de Saneamento. Sistema Nacional de Informações sobre Saneamento: diagnóstico água e esgoto. Disponível em: <http:// wWw.snis.gov.br/diagnostico-agua-e-esgotos/diagnosticoae-2014>. Acesso em: 20 ago. 2015.

BRASIL. (2004) Ministério do Meio Ambiente. Agência Nacional de Águas. Panorama da qualidade das águas superficiais do Brasil 2014. Portal da Qualidade das Águas. Brasília: Agência Nacional de Águas. Disponível em: <http://portalpnqa.ana.gov. br/Publicacao/PANORAMA_DA_QUALIDADE_DAS_AGUAS.pdf> Acesso em: 1. 0 nov. 2015.

COMPANHIA AMBIENTAL DO ESTADO DE SÃO PAULO CETESB. (2005) Variáveis de qualidade de água. São Paulo. Disponível em: <http://aguasinteriores.cetesb.sp.gov.br/wpcontent/uploads/sites/32/2013/11/anexo2 variaveis aguas.zip>. Acesso em: 19 out. 2015

(2009) Qualidade das águas interiores no estado de São Paulo. São Paulo. Disponível em: <http://cetesb.sp.gov.br/aguasinteriores/wp-content/uploads/sites/32/2013/11/variaveis.pdf> Acesso em: 19 out. 2015. 
GONÇALVES, A.A.; CRUZ, M.A.S.; AMORIM, J.R.A.; ARAGÃO, R.; MOTA, P.V.M. (2015) Monitoramento da qualidade da água na sub-bacia hidrográfica do rio Siriri/SE: resultados preliminares. In: Simpósio Brasileiro de Recursos Hídricos, 21. Anais... Brasília.

GOVERNO DO ESTADO DE SERGIPE. (2015) Secretaria de Meio Ambiente e Recursos Hídricos/Superintendência de Recursos Hídricos. Atlas de Recursos Hidricos. Aracaju. (Pen card).

KURODA, E.K.; SANTOS, A.C.A.; QUEIROZ, L.A.; CALIJURI, M.C.; BERNARDO, L. (2005) Determinação de clorofila pelo método espectrofotométrico visando o monitoramento da eficiência do tratamento de águas para abastecimento. In: Congresso Brasileiro de Engenharia Sanitária e Ambiental, 23. Anais... Campo Grande.

LAMPARELLI, M.C. (2004) Degrees of trophy in water bodies of São Paulo: evaluation of monitoring methods. 235p. Tese (Doutorado) - Instituto de Biociências da Universidade de São Paulo, São Paulo.

MACEDO, L.C.B.; ABREU, E.M.; MARQUES, S.L.; SOUZA, R.G.; FONSECA, L.C.; ALVES, J.P.H. (2014) Monitoramento dos Recursos Hídricos do Estado de Sergipe. In: Congresso RESAG-ENQUALAB, 14., São Paulo, SP. Anais... São Paulo.

MAIER, M.H. (1978) Considerações sobre características limnológicas de ambientes lóticos. Boletim do Instituto de Pesca, São Paulo, v. 2, n. 5, p. 75-90.

MARQUES, M.N.; CONTRIM, M.E.; BELTRAME FILHO, O.; PIRES, M.A.F. (2007) Avaliação do impacto da agricultura em áreas de proteção ambiental, pertencentes à bacia hidrográfica do rio Ribeira de Iguape, São Paulo. Química Nova, v. 30, n. 5, p. 1171-1178.

MARQUES, M.N.; SANTOS, A.M.O.; COSTA, A.S.; CORREIA, F.O.; GOMES, S.S.; ALVES, J.P.H. (2011) Water quality evaluation of the lower São Francisco river, Sergipe, Brazil. In: Congresso Mundial da Água, 14., Porto de Galinhas. Anais... Porto de Galinhas.
MARQUES, M.N.; SANTOS, M.S.; CANDIDO, A.S.; ALVES, J.P.H. (2014) Avaliação dos impactos antrópicos nas bacias hidrográficas dos rios São Francisco, Japaratuba, Sergipe, Vaza-Barris, Piauí e Real no estado de Sergipe. In: Simpósio Ítalo-Brasileiro de Engenharia Sanitária e Ambiental, 12., Natal. Anais... Natal.

MELO E SOUZA, R. (2009) Território, planejamento e sustentabilidade: conceitos e práticas. São Cristóvão: Editora UFS.

MORAGAS, W.M. (2005) Análise dos sistemas ambientais do alto Rio Claro - sudoeste de Goiás: contribuição ao planejamento e gestão. Tese (Doutorado em Geografia) - Instituto de Geociências e Ciências Exatas, Universidade Estadual Paulista, Rio Claro.

SANTOS, H.C.R.G. \& MORAES, M.E.B. (2012) Variáveis limnológicas da água e usos do solo: elementos fundamentais para a avaliação de duas microbacias da Bacia Hidrográfica do Rio Almada, Sul da Bahia/Brasil. In: Seminário Nacional de Gestão de Ecossistemas Aquáticos, 1., 2012, Rio de Janeiro. Anais... Rio de Janeiro.

SOARES, A.M. (2008) A dinâmica hidrológica na Bacia do Alto Uberabinha, Minas Gerais. Tese (Doutorado em Geografia) Instituto de Geografia, Universidade Federal de Uberlândia, Uberlândia.

VASCO, A.N.; BRITTO, F.B.; PEREIRA, A.P.S.; MÉLLO JÚNIOR, A.V.M.; GARCIA, C.A.B.; NOGUEIRA, L.C. (2011) Avaliação espacial e temporal da qualidade da água na sub-bacia do Rio Poxim, Sergipe, Brasil. Ambi-Agua, Taubaté, v. 6, n. 1, p. 118-130

VON SPERLING, M. (2007) Quality standards for water bodies in Brazil. In: International Conference on Diffuse Pollution, 11./Joint Meeting of the IWA Diffuse Pollution and Urban Drainage Specialist Groups, 1. Anais... Belo Horizonte. 